\title{
Granulomas at initial diagnosis of Crohn's disease signal a poor outcome
}

\author{
G Watermeyer, MB ChB, FCP, Cert Gastroenterol, MPH; S R Thomson, ChM, FRCS \\ Division of Gastroenterology, Department of Medicine, Faculty of Health Sciences, University of Cape Town and Groote Schuur Hospital, \\ Cape Town, South Africa
}

Corresponding author: G Watermeyer (gillian.watermeyer@uct.ac.za)

\begin{abstract}
Background. Over time, most patients with Crohn's disease (CD) develop strictures or fistulas, resulting in hospitalisations and surgery. Timely therapy with immunomodulators and biologicals may alter this natural history, but carries a significant risk of side-effects.

Objective. To identify factors to predict poor-outcome severe CD at diagnosis, and thus patients who would benefit most from early, aggressive medical therapies.

Methods. CD patients $(n=101)$ with uncomplicated non-stricturing, non-penetrating disease at diagnosis, and with follow-up $>5$ years, were retrospectively analysed using a predefined definition of severe $\mathrm{CD}$ (SCD) over the disease course. Clinical, demographic, laboratory and histological factors at diagnosis associated with SCD and poor outcome were evaluated by univariate and multivariate analysis.

Results. Overall $33.7 \%$ of the cohort developed SCD, and on multivariate Cox proportional hazard analysis the presence of granulomas on endoscopic biopsy at diagnosis was independently associated with development of SCD (hazard ratio (HR) 2.3; 95\% confidence interval (CI) 1.15 - 4.64; $p=0.02$ ). Simple perianal disease was also associated with this outcome (HR 2.49; 95\% CI $1.14-5.41 ; p=0.02$ ). The presence of these variables had a specificity of $99 \%$ and a positive predictive value of $88 \%$.

Conclusion. At diagnosis, factors predictive of SCD in our referral centre were the presence of endoscopic biopsy granulomas and perianal disease. Patients with these risk factors should be considered for early, aggressive medical therapy, as benefit will probably outweigh risk. To our knowledge, this is the first study to show that endoscopic biopsy granulomas in patients with uncomplicated (non-stricturing, nonpenetrating) CD predict the subsequent development of SCD.
\end{abstract}

S Afr Med J 2015;105(6):480-483. DOI:10.7196/SAMJ.9093

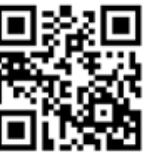

Crohn's disease $(\mathrm{CD})$ is a chronic disorder with variable clinical manifestations and a heterogeneous disease course. The phenotype is defined by age at diagnosis, location, and disease behaviour according to the Montreal classification ${ }^{[1]}$ (Table 1). Behaviour is categorised as the uncomplicated 'non-stricturing and non-penetrating' (B1) phenotype, 'stricturing' (B2) phenotype and 'penetrating' (B3) phenotype. Penetrating CD is also known as fistulising $\mathrm{CD}$. The behaviour of $\mathrm{CD}$ tends to evolve over time to be complicated by the development of strictures, fistulas or abscesses. At diagnosis $80 \%$ of patients have purely inflammatory B1 luminal disease, but by 10 years more than half will have progressed to complicated B2 and B3 phenotypes, often requiring hospitalisation. ${ }^{[2,3]}$ Ultimately $80 \%$ with this progression require surgery. ${ }^{[4]}$

Aggressive medical therapy with immunomodulators (IMMs) such as azathioprine or methotrexate and biologicals may alter this natural history and improve long-term outcomes, but should be introduced early in the disease course, before the development of irreversible complications. ${ }^{[5-7]}$ Such strategies place patients at risk of adverse events, notably infections and malignant disease. ${ }^{[8,9]}$ Populationbased studies have shown that a sizeable num- ber of CD patients will have a benign course, never require surgery and never suffer a flareup severe enough to warrant corticosteroids, ${ }^{[10]}$ and to subject these individuals to drugs with potentially serious side-effects is of concern. In addition, these medications (notably biologicals) are expensive, and access is limited in resource-challenged environments such as ours in South Africa (SA).

Several studies have analysed factors early in the course of $\mathrm{CD}$ that may predict future outcomes and identify those patients at risk of developing complicated $\mathrm{CD}$ and who would receive greatest benefit from early, aggressive therapy. A number of clinical variables have been associated with the subsequent development of pooroutcome $\mathrm{CD}$, notably an initial need for corticosteroids, age $<40$ years, ileocolonic location, stricturing behaviour, weight loss $>5 \mathrm{~kg}$ and perianal disease at diagnosis. ${ }^{[11,12]}$

Several serological markers, such as antiSaccharomyces cerevisiae antibodies, have also been shown to predict disease severity, as have tissue granulomas. ${ }^{[13,14]}$

More recently Siegel et al. ${ }^{[15]}$ developed a model using system dynamics analysis to assess the probability of developing a CD-related complication. This model included patient and disease variables,

\begin{tabular}{l} 
Table 1. Classification of Crohn's disease \\
according to the Montreal classification ${ }^{[1]}$ \\
\hline Age at diagnosis \\
A1: $\leq 16$ years \\
A2: 17 - 40 years \\
A3: >40 years \\
Location \\
L1: Ileal \\
L2: Colonic \\
L3: Ileocolonic \\
L4: Isolated upper GIT ${ }^{*}$ \\
Behaviour \\
B1: Non-stricturing, non-penetrating \\
$\quad$ (inflammatory) \\
B2: Stricturing \\
B3: Penetrating \\
P: Perianal disease modifier ${ }^{\dagger}$ \\
GIT = gastrointestinal tract. \\
*L4 can be added to locations L1 - L3 to indicate \\
coexisting upper GI disease. \\
'P can be added to any behaviour to indicate coexisting \\
perianal disease.
\end{tabular}

serological markers and medical therapies. They demonstrated how data can be transformed into a simple graph showing 
a real-time individualised probability of disease complications. Unfortunately serological markers are not available and are not tested for in our CD subjects, limiting such an approach in our setting. Furthermore, it is unclear whether the predictive clinical variables from European populations are applicable in our local setting, given that our patients differ from those treated in the West. Notably CD is more aggressive in non-Caucasians, the incidence is higher, and common genetic CD susceptibility mutations frequently seen in the developed world are absent in our clinic population. ${ }^{[16,17]}$ In addition, all these European studies included subjects who already had complicated penetrating or stricturing phenotypes at diagnosis, indicating some degree of irreversible damage to the gastrointestinal tract. Ability to evaluate predictive factors for SCD in patients with uncomplicated CD at diagnosis would be of greater value, as these are the patients in whom one may realistically hope to change the natural history of the disease.

To date no study has been done in SA to analyse risk factors predicting poor-outcome $\mathrm{CD}$ in uncomplicated $\mathrm{B} 1$ disease at diagnosis. In view of the potential risk of progression to complicated $\mathrm{CD}$ over time, and the lack of local evidence regarding which patients are at risk, the aim of this study was to evaluate clinical and laboratory indices in subjects with uncomplicated $\mathrm{CD}$, as well as endoscopic biopsy granulomas at the time of diagnosis, and the association with adverse disease outcomes.

\section{Methods}

The research protocol was approved by the Ethics Committee of the University of Cape Town.

A retrospective cohort study was conducted evaluating all patients diagnosed with CD (duration $>5$ years) in our unit to 31 December 2011. Of $567 \mathrm{CD}$ patients registered on our database, 310 were eligible for inclusion. We reviewed their clinical records. Patients were excluded if there were incomplete data at baseline $(n=151)$, if they had not been seen within 12 months $(n=10)$, if there was complex perianal, stricturing or penetrating $\mathrm{CD}$ at diagnosis $(n=37)$, or if they had undergone surgical resection within 1 month of diagnosis $(n=9)$. Two further subjects were excluded because their diagnosis was revised. Overall $84 \%$ of patients with data at diagnosis had B1 disease. Complex perianal disease was defined according to the American Gastroenterology Association recommendation as 'fistulas that are high intersphincteric, high transsphincteric, extrasphincteric or suprasphincteric, have multiple external openings, are associated with a perianal abscess, fistulise to adjacent organs, are associated with the presence of an anorectal stricture or associated with the presence of active rectal disease. ${ }^{[18]}$

Severe CD (SCD) was defined (as previously described by Loly et $a l .{ }^{[11]}$ as the presence of any of the following over the entire disease course: 'complex perianal disease; any colonic resection; two or more small-bowel resections; a single small-bowel resection more than 50 $\mathrm{cm}$ in length; or construction of a definitive stoma'.

Patients were followed up from CD diagnosis until 31 December 2011, or alternatively until the development of SCD.

The following data were collected at diagnosis and during follow-up: demographics, clinical and biochemical variables, histological evidence of granulomas, corticosteroid use, hospitalisations, surgeries, creation of a definitive stoma, progression from B1 to B2 or B3 phenotypes, IMMs or biological use, and the development of perianal fistulas.

\section{Statistical analysis}

All continuous variables evaluated were not normally distributed and are therefore expressed as medians and interquartile ranges (IQRs). Categorical variables were compared using the $\chi^{2}$ or Fisher's exact test, as appropriate. In addition, univariate and multivariate Cox proportional hazard analysis was performed to identify risk factors associated with time to the development of SCD. Variables with $p$-values $\leq 0.2$ were included in the multivariate model. The Kaplan-Meier method was used to estimate the cumulative probability of developing SCD as well as progression from $\mathrm{B} 1$ to $\mathrm{B} 2$ or $\mathrm{B} 3$ phenotypes over time.

\section{Results}

Overall, 101 subjects were eligible for inclusion in the study. The median age at diagnosis was 31 years (IQR 23 - 39), and 61.4\% (62/101) were female. At diagnosis $36.6 \%$ (37/101) had isolated ileocaecal (L1) disease, $27.7 \%$ (28/101) isolated colonic (L2) disease and 35.6\% (36/101) ileocolonic (L3) disease. Six patients (5.9\%) also had involvement of the upper GIT, 13.9\% (14/101) had evidence of simple perianal disease, $65.3 \%$ (66/101) were active cigarette smokers, 55.4\% (56/101) were treated with corticosteroids for the first flare of disease, and 41.6\% (42/101) had noncaseating granulomas on endoscopic biopsy at diagnosis.

Overall, 33.7\% of patients (34/101) developed SCD over their disease course. The median time to the development of SCD was 103 months (IQR 60 - 144). The cumulative probability of developing SCD was $11 \%, 21 \%$ and $30 \%$ at 1,5 and 10 years after diagnosis, respectively. Predictors at diagnosis associated with the time to development of SCD are presented in Table 2 . After multivariate analysis, only perianal disease (hazard ratio (HR) 2.49; 95\% confidence interval (CI) 1.14 - 5.41; $p=0.02$ ) and granulomas (HR 2.3; 95\% CI $1.15-4.64 ; p=0.02$ ) at diagnosis were independently associated with time to the development of SCD. There were no statistically significant differences when evaluating patients with or without granulomas. There was also no difference in baseline variables in subjects with or without perianal CD.

Kaplan-Meier curves for the development of SCD according to the presence or absence of these two factors are shown in Fig. 1. Sensitivity, specificity, positive predictive value and negative predictive value of a logistic regression model including these two risk factors were $21 \%, 99 \%, 88 \%$ and $71 \%$, respectively. Of patients with B1 disease at diagnosis, $42.3 \%$ progressed to $\mathrm{B} 2$ or B3 phenotype over time. The cumulative probability of developing either of these complicated phenotypes was $13 \%$ at 1 year, $24 \%$ at 2 years, $33 \%$ at 5 years and $43 \%$ at 10 years. The median time to progression was 24 months (IQR $11-78$ ). None of the baseline parameters assessed was significantly associated with time to $\mathrm{B} 2$ or $\mathrm{B} 3$ progression.

Forty patients (39.6\%) with a B1 phenotype at diagnosis ultimately required a surgical resection, while $26(25.7 \%)$ underwent two or more surgical resections. The presence of granulomas at diagnosis was the only predictor for more than one resection during follow-up (OR 4.7; $95 \%$ CI 1.8 - 12.3; $p=0.002$ ).

\section{Discussion}

Our results are consistent with previous reports in that the majority of $\mathrm{CD}$ patients with uncomplicated $\mathrm{B} 1 \mathrm{CD}$ at diagnosis went on to a disabling disease course over time. We only included subjects with purely inflammatory $\mathrm{B} 1$ disease at diagnosis, as most patients who have stricturing or penetrating phenotypes or complex perianal $\mathrm{CD}$ would already be considered to have complicated disease and therefore to be candidates for aggressive therapy with IMMs and biologicals. ${ }^{[5]}$ As such, predicting poor-outcome $\mathrm{CD}$ in these patients is not as valuable as in patients with uncomplicated disease, in whom the decision to start disease-modifying therapies has far more important consequences. Overall, $33.7 \%$ of our cohort developed SCD over their disease course. This is almost identical to the figure reported by Loly et al. ${ }^{[1]}$ in their Liège cohort. In keeping with several other studies, perianal disease emerged as a strong predictor of poor-outcome $C D{ }^{[12,19]}$ Our analysis also revealed that endoscopic tissue biopsy granulomas at diagnosis were associated with earlier development of SCD and were 
Table 2. Risk factors at diagnosis significantly associated with time to development of SCD, analysed with the Cox proportional hazard method

\begin{tabular}{|c|c|c|c|c|}
\hline Risk factors at diagnosis & $\begin{array}{l}\text { Severe CD } \\
(N=34,33.7 \%)\end{array}$ & $\begin{array}{l}\text { Non-severe CD } \\
(N=67,66.3 \%)\end{array}$ & $\begin{array}{l}\text { Unadjusted HR; } \\
\text { 95\% CI; } p \text {-value }\end{array}$ & $\begin{array}{l}\text { Adjusted HR; } \\
95 \% \mathrm{CI} ; p \text {-value }\end{array}$ \\
\hline Female gender, $n(\%)$ & $18(52.9)$ & $44(65.7)$ & $0.64 ; 0.33-1.26 ; 0.20$ & $0.59 ; 0.32-1.1 ; 0.1$ \\
\hline \multicolumn{5}{|l|}{ Race, $n(\%)$} \\
\hline White & $8(23.5)$ & $13(19.4)$ & 1; Reference; 0.89 & \multirow[t]{3}{*}{ Not included } \\
\hline Black & $2(5.9)$ & $4(6.0)$ & $0.88 ; 0.13-5.9$ & \\
\hline Coloured & $24(70.6)$ & $50(74.6)$ & $0.86 ; 0.32-2.329$ & \\
\hline \multicolumn{5}{|l|}{ Age (years), $n(\%)$} \\
\hline $\mathrm{A} 1,<17$ & $4(11.8)$ & $47(6.0)$ & \multirow[t]{3}{*}{ 1; Reference; 0.28} & \multirow[t]{3}{*}{ Not included } \\
\hline A2, $17-40$ & $25(73.2)$ & $45(67.2)$ & & \\
\hline $\mathrm{A} 3,>40$ & $5(14.7)$ & $18(26.9)$ & & \\
\hline Perianal disease, $n(\%)$ & $25(73.5)$ & $5(7.5)$ & $3.05 ; 1.42-6.56 ; 0.004$ & $2.49 ; 1.14-5.41 ; 0.02$ \\
\hline \multicolumn{5}{|l|}{ Location, $n(\%)$} \\
\hline $\mathrm{L} 1$ & $14(41.2)$ & $23(34.3)$ & \multirow[t]{3}{*}{ 1; Reference; 0.52} & \multirow[t]{3}{*}{ Not included } \\
\hline $\mathrm{L} 2$ & $7(20.6)$ & $21(31.3)$ & & \\
\hline L3 & $13(38.2)$ & $23(34.3)$ & & \\
\hline Extent of SB $>20 \mathrm{~cm}, n(\%)$ & $18(52.9)$ & $43(64.2)$ & $1.03 ; 0.98-1.08 ; 0.26$ & Not included \\
\hline Colonic segments involved $(n)$, mean (range) & $2(0-3)$ & $1(0-3)$ & $0.94 ; 0.8-1.11 ; 0.45$ & Not included \\
\hline Upper GIT, $n(\%)$ & $3(8.8)$ & $37(4.5)$ & $1.65 ; 0.5-5.4 ; 0.41$ & Not included \\
\hline Rectal involvement, $n(\%)$ & $6(17.6)$ & $13(19.4)$ & $0.96 ; 0.4-2.32 ; 0.93$ & Not included \\
\hline Family history, $n(\%)$ & $2(5.9)$ & $57(7.5)$ & $0.97 ; 0.23-4.04 ; 0.96$ & Not included \\
\hline Current smoker*, $n(\%)$ & $20(58.8)$ & $46(68.7)$ & $0.59 ; 0.30-1.18 ; 0.14$ & Not included \\
\hline Appendicectomy, $n(\%)$ & $3(8.8)$ & $2(3.0)$ & $1.68 ; 0.51-5.48 ; 0.39$ & Not included \\
\hline$>5$ kg weight loss, $n(\%)$ & $23(67.6)$ & $34(50.7)$ & $1.89 ; 0.91-3.86 ; 0.09$ & $1.82 ; 0.87-3.8 ; 0.11$ \\
\hline Steroids, $n(\%)$ & $19(55.9)$ & $38(56.7)$ & $1.13 ; 0.57-2.24 ; 0.70$ & Not included \\
\hline EIMs, $n(\%)$ & $8(23.5)$ & $18(26.9)$ & $0.8 ; 0.35-1.72 ; 0.53$ & Not included \\
\hline Granulomas, $n(\%)$ & $21(61.8)$ & $21(31.3)$ & $2.33 ; 1.17-4.66 ; 0.02$ & $2.3 ; 1.15-4.64 ; 0.02$ \\
\hline
\end{tabular}

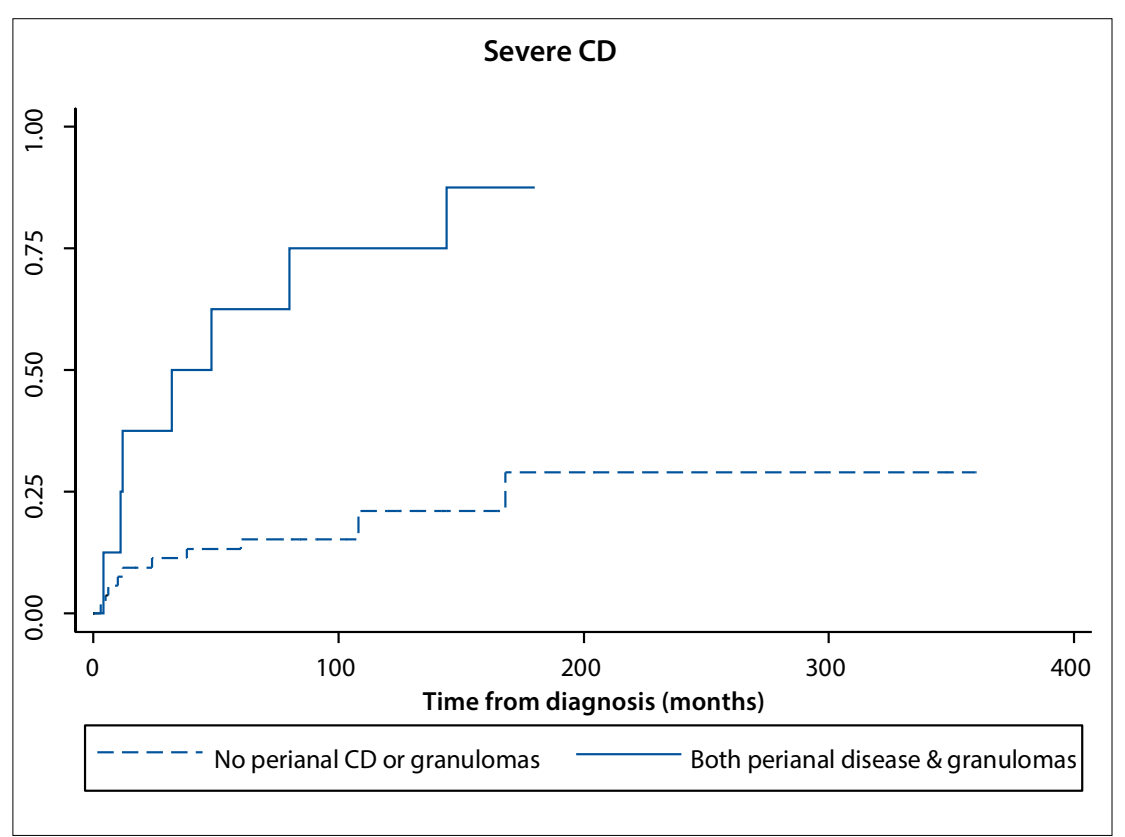

Fig. 1. Kaplan-Meier curves for the development of SCD according to the presence or absence of perianal disease and granulomas at diagnosis in patients with B1 phenotype. the only predictor for more than one surgical procedure during follow-up.

Granulomas are considered a histological characteristic of CD. However, in reality fewer than $50 \%$ of patients will have them on biopsy specimens, and their pathogenesis is unknown. Several studies evaluating poor-outcome CD have included granulomas in analysis, and although results are conflicting, most favour granulomas as a predictor of aggressive $\mathrm{CD}$. A 2010 meta-analysis concluded that granulomas appear to be associated with a higher number of recurrences and surgeries. ${ }^{[14]}$ However, it is difficult to draw conclusions from this analysis given significant heterogeneity between studies. A study by Freeman ${ }^{[20]}$ showed that the presence of granulomas was linked to a more complicated disease course, with more extensive ileocolonic and upper gastrointestinal tract involvement and more penetrating disease. In addition, Heresbach et al. ${ }^{[21]}$ demonstrated that the presence of granulomas independently predicted the need 
for surgical resection. More recent publications have confirmed these findings. ${ }^{[22]}$ However, many of these studies are confounded by the inclusion of granulomas found in surgical resection specimens as well as those found on endoscopic biopsies. Furthermore, analysis included the development of granulomas at any point over the disease course. Molnár et al. ${ }^{[23]}$ performed a small prospective study which showed that at diagnosis granulomas on endoscopic biopsy were associated with a higher need for surgery or IMMs; these authors, however, included subjects with B2 and B3 disease at diagnosis. Patients with granulomas also had significantly higher $\mathrm{CD}$ activity index values at diagnosis than those without, a finding that was not adjusted for in analysis. Similarly, a paediatric study showing that endoscopic biopsy granulomas at diagnosis were associated with increased need for surgery included children with complex perianal CD. ${ }^{[24]}$ To our knowledge, this study is the first to include only endoscopic tissue biopsy granulomas at the time of first diagnosis in uncomplicated B1 CD.

It is unclear how granulomas may influence $C D$ outcomes. One possible explanation is an association with autophagy genetic variants. Autophagy is a process involved in the elimination of intracellular bacteria, and this pathway appears to be altered in CD. Reduced clearance of pathogenic bacteria may drive the chronic inflammation observed in these patients. Genetic variants in autophagy genes, notably autophagy-related gene 16-like 1 (ATG16L1) and immunityrelated GTPase M (IRGM), have been associated with susceptibility to CD. A recent study from Leuven evaluated surgical specimens from $464 \mathrm{CD}$ patients and found associations between granulomas and several autophagy gene variants. ${ }^{[22]}$

Another possible mechanism that could explain the association of granulomas with poor-outcome $\mathrm{CD}$ is the observation that granulomas can cause lymphatic obstruction, which could lead to chronic tissue oedema with subsequent irreversible fibrosis. ${ }^{[25]}$

\section{Study limitations}

Our study has a number of limitations. Firstly, we excluded patients with incomplete data at diagnosis. This is a potential source of selection bias; however, it is likely that these data were missing at random and not correlated with CD severity or outcome. Another potential source of bias is that only patients with complete follow-up data were included. This could introduce selection bias, as patients lost to follow-up may have had less severe disease than those who continued to be seen in our clinic. However, the cumulative probabilities of progressing from $\mathrm{B} 1$ disease at diagnosis to stenosing or penetrating phenotypes is almost identical to those reported in a large population-based study from Olmsted County, Minnesota, USA. ${ }^{[26]}$ Furthermore, the baseline demographics (age and gender) as well as disease location and behaviour of our study participants were very similar to those reported in a New Zealand population-based $\mathrm{CD}$ cohort. ${ }^{[19]}$ Finally, our study is limited by the retrospective nature of the analysis; in many subjects the number and site of endoscopic biopsies, and the number of granulomas, were not recorded.

Despite these limitations, our study has provided some valuable information. This is the first SA study to identify predictors of pooroutcome $\mathrm{CD}$ in patients with $\mathrm{B} 1$ disease. This will aid the decision in our setting about when to risk aggressive medical therapies early in the disease course. As emphasised by Louis et al..$^{[27]}$ in a recent review, there are two possible errors in managing CD: overtreating patients who will have benign disease, and undertreating those who will go on to develop poor outcomes.

In our study, perianal disease and granulomas at diagnosis were very specific for the development of SCD over the disease course. Only $1 \%$ of individuals with these two predictors at diagnosis would be falsely classified as having SCD and therefore subjected to aggressive therapies unnecessarily. In addition, these two risk factors are routinely assessed at baseline and do not require expensive blood testing or genetic analysis.

\section{Conclusion}

Data from this retrospective study have shown that $34 \%$ of our cohort developed severe poor-outcome CD over their disease course. Our study has identified several factors at diagnosis of B1 CD that are predictive of this outcome. Notably, perianal disease and endoscopic biopsy granulomas were independently associated with time to the development of SCD. The latter is a novel finding and merits further prospective evaluation in different populations as a potential factor that accurately predicts progression from $\mathrm{B} 1$ disease to $\mathrm{SCD}$ and could therefore be used to identify patients who merit selection for aggressive medical therapies.

\section{References}

1. Satsangi J, Silverberg MS, Vermeire S, Colombel JF. The Montreal classification of inflammatory bowel disease: Controversies, consensus, and implications. Gut 2006;55(6):749-753. [http://dx.doi org/10.1136/gut.2005.082909

2. Cosnes J, Cattan S, Blain A, et al. Long-term evolution of disease behaviour of Crohn's disease. Inflamm Bowel Dis 2002;8(4)244-250. [http://dx.doi.org/10.1097/00054725-200207000-00002]

3. Louis E, Collard A, Oger AF, et al. Behaviour of Crohn's disease according to the Vienna classification: Changin pattern over the course of the disease. Gut 2001;49(6):777-782. [http://dx.doi.org/10.1136/gut.49.6.777]

Mekhjian HS, Switz DM, Watts HD, et al. National Cooperative Crohn's Disease Study: Factors determining recurrence of Crohn's disease after surgery. Gastroenterology 1979;77(4):907-913.

Dignass A, van Assche G, Lindsay JO, et al. The second European evidence-based consensus on the diagnosis and management of Crohn's disease: Current management. J Crohns Colitis 2010:4(1):2862. [http://dx.doi.org/10.1016/j.crohns.2009.12.002 plus corrigendum http://dx.doi.org/10.1016/j. 62. [http://dx.doi.oig/

Colon J JF S Crohn's disease. N Engl J Med 2010;362(13):1383-1395. [http://dx.doi.org/10.1056/NEJMoa0904492]

D'Haens G, Baert F van Assche G, et al. Early combined immunosuppression or conventional D'Haens G, Baert F, van Assche G, et al. Early combined immunosuppression or conventional
management in patients with newly diagnosed Crohn's disease: An open randomised trial. Lancet management in patients with newly diagnosed Crohn's disease: An open r
2008;371(9613):660-667. [http://dx.doi.org/10.1016/S0140-6736(08)60304-9]

8. Toruner M, Loftus EV Jr, Harmsen WS, et al. Risk factors for opportunistic infections in patients with inflammatory bowel disease. Gastroenterology 2008;134(4):929-936. [http://dx.doi.org/10.1053/. gastro.2008.01.012]

9. Lichtenstein GR, Feagan BG, Cohen RD, et al. Serious infections and mortality in association with therapies for Crohn's disease: TREAT registry. Clin Gastroenterol Hepatol 2006;4(7):621-630. [http:// dx.doi.org/10.1016/j.cgh.2006.03.002

0. Munkholm P, Langholz E, Davidsen M, et al. Frequency of glucocorticoid resistance and dependency in Crohn's disease. Gut 1994;35(3):360-362.

1. Loly C, Belaiche I Louis E. Predictors of severe Crohn's disease. Scand J Gastroenterol 2008:43(8):948954. [http://dx.doi.org/10.1080/00365520801957149]

12. Beaugerie L, Seksik P, Nion-Larmurier I, et al. Predictors of Crohn's disease. Gastroenterology 2006;130(3):650-656. [http://dx.doi.org/10.1053/.j.gastro.2005.12.019]

13. Mow W, Vasiliauskas E, Lin Y, et al. Association of antibody responses to microbial antigens and complications of small bowel Crohn's disease. Gastroenterology 2004;126(2):414-424. [http://dx.doi. org/10.1053/j.gastro.2003.11.015]

14. Simillis $\mathrm{C}$, Jacovides $\mathrm{M}$, Reese $\mathrm{G}$, et al. Meta-analysis of the role of granulomas in the recurrence of Croh disease. Dis Colon Rectum 2010;53(2):77-185. [http://dx.doi.org/10.1007/DCR.0b013e3181b7bfb0]

5. Siegel CA, Siegel LS, Hyams JS, et al. Real-time tool to display the predicted disease course an treatment response for children with Crohn's disease. Inflamm Bowel Dis 2011;17(1):30-38. [http:// dx.doi.org/10.1002/ibd.21386]

16. Zaahl MG, Winter T, Warnich L, et al. Analysis of the three common mutations in the CARD15 gene (R702W, G908R and 1007fs) in South African coloured patients with inflammatory bowel disease. Mol Cell Probes 2005;19(4):278-281. [http://dx.doi.org/10.1016/j.mcp.2005.03.001]

17. Basson A, Swart R, Jordaan E, et al. The association between race and Crohn's disease phenotype in the Western Cape population of South Africa, defined by the Montreal Classification System. PLoS One 2014;9(8):e104859. [http://dx.doi.org/10.1371/journal.pone.0104859]

8. Sandborn WJ, Fazio VW, Feagan BG, et al, American Gastroenterological Association Clinical Practice Committee. AGA technical review on perianal Crohn's disease. Gastroenterology 2003;125(5):15081530. [http://dx.doi.org/10.1016/.j.gastro.2003.08.025]

19. Tarrant KM, Barclay ML, Frampton CM, et al. Perianal disease predicts changes in Crohn's diseas phenotype - results of a population-based study of inflammatory bowel disease phenotype. Am Gastroenterol 2008;103(12):3082-3093. [http://dx.doi.org/10.1111/j.1572-0241.2008.02212.x]

20. Freeman HJ. Granuloma-positive Crohn's disease. Can J Gastroenterol 2007;21(9):583-587.

1. Heresbach D, Alexandre JL, Branger B, et al. Frequency and significance of granulomas in a cohort of incident cases of Crohn's disease. Gut 2005;54(2):215-222. [http://dx.doi.org/10.1136/gut.2004.041715

22. Brinar M, Vermeire S, Cleynen I, et al. Genetic variants in autophagy-related genes and granulom formation in a cohort of surgically treated Crohn's disease patients. J Crohns Colitis 2012;6(1):43-50. [http://dx.doi.org/10.1016/j.crohns.2011.06.008]

23. Molnár T, Tiszlavicz L, Gyulai C, Nagy F, Lonovics J. Clinical significance of granuloma in Crohn's disease. World J Gastroenterol 2005;11(20):3118-3121.

24. Markowitz J, Kahn E, Daum F. Prognostic significance of epithelioid granulomas found in rectosigmoid biopsies at the initial presentation of pediatric Crohn's disease. J Pediatr Gastroenterol Nutr 1989;9(2):182-186. [http://dx.doi.org/10.1097/00005176-198908000-00009]

25. Van Kruiningen HJ, Hayes AW, Colombel JF. Granulomas obstruct lymphatics in all layers of the intestine in Crohn's disease. APMIS 2014;122(11):1125-1129. [http://dx.doi.org/10.1111/apm.12268]

26. Thia KT, Sandborn WJ, Harmsen, et al. Risk factors associated with progression to intestinal complications of Crohn's disease in a population-based cohort. Gastroenterology 2010;139(4):11471155. [http://dx.doi.org/10.1053/j.gastro.2010.06.070]

27. Louis E, Belaiche J, Reenaers C. Tailoring the treatment to the individual in Crohn's disease. Ther Adv Gastroenterol 2009;2(4):239-244. [http://dx.doi.org/10.1177/1756283X09337180]

Accepted 21 April 2015 